\title{
IMPLEMENTASI KEBIJAKAN PENATAAN, PEMBINAAN DAN PENGAWASAN TOKO MODERN DI KECAMATAN KAJEN KABUPATEN PEKALONGAN
}

\author{
Edhi Setiawawn ${ }^{1}$ dan Retno Sunu Astuti ${ }^{2}$
}

\begin{abstract}
Modern Stores in Kajen Subdistrict increase rapidly in terms of numbers. The purpose of this study is to analyze the Implementation of The Modern Store Management, Guidance and Supervision Policy in Kajen Sub District, Pekalongan Regency and to analyze the supporting and inhibiting factors of the Implementation of the Policy. This study uses a qualitative approach, with the analysis of the policy implementatioin of the 5 C Protocol Adil Najam Model. The location of the study in Kajen Sub District. Modern Store policy implementation in Kajen Subdistrict seen from the arrangement (1) has referred to the RTRW Regional Regulation, but there is no legal protection of the Kajen Sub District RDTR and Zoning Arrangement (2) Not all of the Modern Stores construction has IUTM, not all meet the distance requirement and the stores was built at one side of the same road. The Implementation when viewed from the coaching side (1) The OPD coaching executor newly focuses on the Modern Stores Networking, (2) Partnerships with SMEs are not much connected yet, only implemented by Non-Networked Modern Stores. The Implementation when viewed from supervision (1) There is no reporting from the Modern Stores (2) There is no firmness in enforcement of the Perda. The supporting factors of the implementation of the policy are (1) the clarity of the implementers of the implementation and the authority, (2) the existence of a legal protection ranging from local regulations, regent regulation, Service standard, SOP, (3) conducive environmental conditions between the Modern Market and the traditional stores, while the inhibitor factors include (1) weak coordination of the policy implementors, (2) limited personnel lacking firmness in law enforcement, (3) no firmness in enforcement of rules, (4) low awareness of Modern Stores in managing Modern Store Business Licenses (IUTM) (5) limited public understanding of policy. The suggestions that I can convey are (1) need more intensive guidance (2) strengthening of SMEs (3) improving coordination (4) need to increase capacity and motivation for implementing policy implementation (5) need further research related to content from the Modern Store Policy
\end{abstract}

Keywords: Policy Implementation, Modern Stores, Commitment, contex, client and coalition

\section{PENDAHULUAN}

Pasar menjadi inti dari usaha atau industri dan merupakan mata rantai yang menghubungkan antara produsen dan konsumen, ajang pertemuan antara penjual dan pembeli, antara dunia usaha dan masyarakat. (Gilarso, 2004 : 109). Kehadiran peritel Modern pada awalnya tidak mengancam pasar tradisional. Peritel Modern yang menyasar

\footnotetext{
${ }^{1}$ Mahasiswa Prodi S2 IImu Administrasi, Departemen Adm Publik, Universitas Diponegoro

${ }^{2}$ Dosen Prodi S2 IImu Administrasi, Departemen Adm Publik, Universitas Diponegoro
} 
konsumen dari kalangan menengah ke atas, saat itu lebih menjadi alternatif dari pasar tradisional yang identik dengan kondisi pasar yang kumuh, dengan tampilan dan kualitas yang buruk, serta harga jual rendah dan sistem tawar menawar konvensional (Amin, $2011: 1)$

Kenaikan Toko Modern di Kabupaten Pekalongan pada tahun 2018 sebesar 3,74 \% dibandingkan tahun 2017, sebesar 57,35\% pada tahun 2017 dibandingkan tahun 2015, dan sebesar 44,68\% pada tahun 2012 ke 2015.

Untuk melaksanakan penataan, pembinaan dan pengawasan Toko Modern di Kabupaten Pekalongan telah diterbitkan Peraturan Daerah Kabupaten Pekalongan Nomor 10 Tahun 2015 tentang Perubahan atas Peraturan Daerah Kabupaten Pekalongan Nomor 1 Tahun 2014 tentang Penataan, Pembinaan dan Pengawasan Pasar Tradisional, Pusat Perbelanjaan dan Toko Modern,

Kebijakan tersebut dimaksudkan untuk memberdayakan Pasar Tradisional agar dapat tumbuh dan berkembang secara serasi, saling memerlukan, saling memperkuat serta saling menguntungkan, bersamaan dengan berkembangnya usaha perdagangan eceran yang berbentuk pusat perbelanjaan maupun toko modern

Keberadaan Toko Modern yang belum memiliki izin namun sudah beroperasional menjadi alasan peneliti untuk melakukan analisis Faktor pendukung dan penghambat Implementasi Kebijakan dengan melihat dari sisi contex, commitment dan client and coalition. Apakah hal tersebut disebabkan oleh pelaksana implementasi kebijakan atau disebabkan karena faktor dari Toko Modern.

Pemilihan Lokus penelitian di Kecamatan Kajen dengan pertimbangan (1) Kecamatan Kajen merupakan Ibukota Kabupaten, sebagai rujukan bagi kecamatan lain (2) jumlah Toko Modern pada tahun 2018 sebanyak 18 buah (terbanyak keduasetelah Kecamatan Kedungwuni), (3) terdapat 3 Toko Modern berjejaring yang beroperasi saat ini yang keberadaanya belum sesuai Perda.

\section{Kerangka Teori}

Analisis faktor pendukung dan penghambat implementasi kebijakan penataan, pembinaan dan pengawasan Toko Modern di Kecamatan Kajen Kabupaten Pekalongan dengan menggunakan 5C Protocol Adil Najam. 


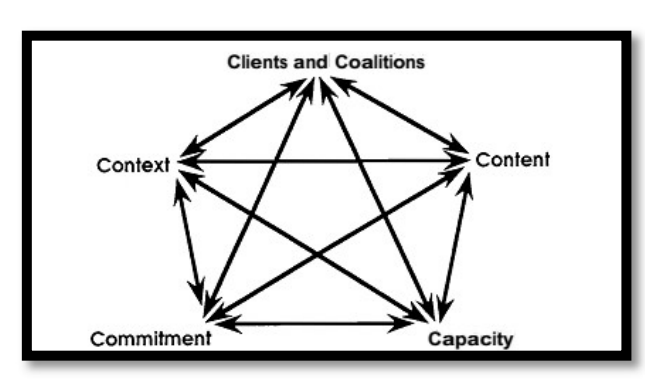

Sumber : Adil Najam; 1995:v

Peneliti memilih model 5C Protocol Adil Najam karena merasa model ini yang paling tepat untuk mengetahui faktor pendukung dan penghambat dengan melihat dari sisi context, commitment dan client and coalition. Dengan menggunakan model $5 \mathrm{C}$ Protocol diharapkan dapat dianalisis lebih jauh faktor pendukung dan penghambat isi /substansi kebijakan penataan, pembinaan dan pengawasan Toko Modern sehingga dapat menyeselaikan permasalahan, prosedur operasi dalam proses implementasi, komitmen pelaksana implementasi di berbagai tingkatan, kapasitas administrasi pelaksana implementasi dan dukungan dari pihak pihak yang bersinggungan dengan implementasi kebijakan.

\section{Metode Penelitian}

Penelitian ini menggunakan pendekatan deskriptif kualitatif. Teknik pengumpulan data dilakukan dengan metode wawancara, observasi, Studi kepustakaan, dan dokumentasi. Lokasi penelitian bertempat di Kecamatan Kajen yaitu pada OPD pelaksana implementasi dan Toko Modern..

Fenomena penelitian ini mecakup: Pertama Implementasi Kebijakan Penataan, Pembinaan dan Pengawasan Toko Modern, meliputi meliputi penataan, Pembinaan, Pengawasan Toko Modern di Kecamatan Kajen Kabupaten Pekalongan.Kedua faktor pendukung dan penghambat Implementasi Kebijakan Penataan, Pembinaan dan Pengawasan Toko Modern di Kecamatan Kajen Kabupaten Pekalongan, meliputi ContextCommitment dan Client and Coalitions

Context dalam implementasi kebijakan adalah bagaimana pembagian tupoksi diantara implementor, bagaimana koordinasi yang dilaksanakan dalam rangka mencapai keberhasilan implementasi kebijakan. 
Commitment dalam implementasi kebijakan adalah bagaimana komitmen implementor dalam melaksanakan penataan, pembinaan dan pengawasan toko modern di Kecamatan Kajen Kabupaten Pekalongan.

Client and Coalitions dalam implementasi kebijakan adalah bagaimana dukungan dari klien dan koalisi yang kepentingannya ditingkatkan atau terancam oleh Kebijakan yang ada, yaitu dari masyarakat dan Toko Modern.

Teknikanalisis data dilakukan melalui beberapa tahapan, yaitu pengumpulan data (data collection), penyajian data (data display), verifikasi data (data verification), dan penarikan kesimpulan (drawing conclusion).

\section{PEMBAHASAN}

\section{Penataan}

Penataan adalah segala upaya yang dilakukan oleh pemerintah daerah untuk mengatur dan menata keberadaan dan pendirian toko swalayan di suatu daerah, agar tidak merugikan dan mematikan pasar tradisional, usaha mikro, kecil, menengah dan koperasi yang ada

Toko Modern di Kecamatan Kajen sudah mengacu kepada Rencana Tata Ruang Wilayah Kabupaten Pekalongan Tahun 2011-2031, namun belum belum mengacu kepada Rencana Detil Tata Ruang (RDTR) Kecamatan Kajen dan pengaturan zonasi

Pendirian Toko Modern di Kecamatan Kajen sudah memenuhi ketentuan Garis Sempadan Bangunan (GSB)

Operasional Toko Modern belum semuanya telah mengantongi Izin Usaha Toko Modern (IUTM). Masih banyak yang dalam proses perizinan bahkan terdapat 4 (empat) Toko Modern yang belum memiliki izin sudah beroperasional.. Dari 18 Toko Modern yang telah memiliki IUTM baru 3 Toko, atau 16,57 \%.

Toko Modern Berjejaring yang memenuhi ketentuan jarak hanya 10 Toko, sedangkan untuk Toko Modern Non Berjejaring dari 5 Toko semua tidak memenuhi ketentuan jarak. Namun untuk Toko Modern Non Berjejaring tersebut tidak melanggar Perda karena walaupun jaraknya kurang dari 500 meter, toko tersebut merupakan pengembangan dari toko non modern yang sudah ada.

Sedangkan keberadaan 3 Toko Modern Berjejaring yang tidak memenuhi ketentuan jarak, Toko tersebut didirikan sebelum terbitnya Perda Nomer 1 tahun 2014, belum memiliki IUTM masih menggunakan SIUP (Surat Izin Usaha Perdagangan). Toko 
tersebut mendapat diberi waktu 3 tahun untuk beroperasional, namun untuk selanjutnya harus mematuhi regulasi yang ada, yaitu beralih ke Toko Modern Non Berjejaring atau Toko Biasa atau Tutup.

Perbup Nomor 23 Tahun 2016 pada pasal 4 ayat (2) mensyaratkan bahwa pendirian Toko Modern tidak diperkenankan pada satu sisi dalam ruas jalan yang sama. Ketentuan ini dalam pendirian Toko Modern di Kecamatan Kajen tidak sesuai dengan ketentuan. Bahkan pelaksana implementasi tidak mampu mengambil mengambil keputusan karena di dalam Perda dan Perbup dirasakan kurang jelas terkait jarak antar Toko Modern pada satu sisi dalam ruas jalan yang sama.

\section{Pembinaan}

Berdasarkan Perda Nomor 10 Tahun 2015 yang dimaksud dengan Pembinaan adalah suatu kegiatan yang meliputi perlindungan, pemberdayaan dan penataan.

Perlindungan adalah segala upaya pemeritah daerah dalam melindungi pasar tradisional, usaha mikro, kecil, menengah dan koperasi dari persaingan yang tidak sehat dengan pasar modern, toko swalayan dan sejenisnya, sehingga tetap eksis dan mampu berkembang menjadi lebih baik sebagai layaknya suatu usaha

Peranan perlindungan memiliki keterkaitan yang kuat dengan penataan. Dimana tujuan dari penataan dan perlindungan adalah pasar tradisional, usaha mikro, kecil, menengah dan koperasi terlindungi dari persaingan yang tidak sehat dengan pasar modern, toko swalayan dan sejenisnya.

Dalam pelaksanaanya komponen ini masih belum optimal, karena pendirian Toko Modern masih banyak yang belum memenuhi ketentuan jarak dari Pasar Tradisional

Pemberdayaan adalah segala upaya pemerintah daerah dalam melindungi pasar tradisional, usaha mikro, kecil, menengah dan koperasi agar tetap eksis dan mampu berkembang menjadi suatu usaha yang berkualitas baik dari aspek manajemen dan fisik/tempat agar dapat bersaing dengan pasar modern.

Pembinaan telah dilaksanakan oleh Dinas Perindagkop UKM walaupun belum optimal dalam pelaksanaanya, masih terbatas kepada Toko Modern Berjejaring, belum menyentuh kepada Toko Modern Non Jejaring. Kemitraan yang diharapkan dapat terjalin dengan UKM belum dapat terlaksana khususnya oleh Toko Modern Berjejaring. Kemitraan dengan UKM baru dapat dilaksanakan oleh Toko Modern Non Berjejaring. 
Kemitraan yang terjadi antara Toko Modern dan UKM lebih banyak merupakan hasil inisiatif dari Toko Modern sendiri

\section{Pengawasan}

Pengawasan adalah suatu kegiatan yang membandingkan apa yang dijalankan, dilaksanakan, atau diselenggarakan itu dengan apa yang dikehendaki, direncanakan, atau diperintahkan.

Toko Modern di Kecamatan Kajen tidak pernah memberikan laporan rutin terkait omset penjualan, jumlah UMKM yang bermitra dan pola kemitraan, jumlah tenaga kerja yang diserap.. Dengan demikian maka Dinperindagkop UKM tidak dapat melakukan pengawasan pelaksanaan kemitraan dan melakukan evaluasi pengelolaan toko modern

Dinperindagkop UKM, Satpol PP Damkar belum pernah melaksanakan penertiban, walaupun telah diketahui bahwa semua Toko Modern melanggar jam Operasional. Bahkan untuk Alfamart Pasar Kajen memiliki jam operasional 24 Jam, dan belum ada izin khusus. Sampai saat ini belum pernah ada teguran baik tertulis maupun lisan terkait dengan hal tersebu

Pengawasan berupa monitoring di lapangan yang telah dilaksanakan masih sangat terbatas, yaitu kerjasama dengan Badan POM dalam melaksanakan pengawasan batas kadaluarsa produk. Pengawasan tidak dilaksanakan secara optimal karena dari Dinperindagkop UKM selaku OPD teknis pembina Toko Modern, Dinas PM PTSP Naker selaku penerbit Izin Usaha Toko Modern (IUTM), dan dari Satpol PP Damkar merasa kondisi di Kabupaten Pekalongan masih kondusif, tidak ada konflik antara Toko Modern dan Pasar Tradisional dan Toko Konvensional. Selain itu tidak ada keberanian dan ketegasan dalam menegakan Regulasi yang ada terkait Toko Modern, baik dari perizinan, jarak, jam operasional.

\section{Faktor Pendukung dan Penghambat}

\section{Context}

Implementasi Kebijakan Toko Modern jika dilihat dari Context bertujuan untuk mengetahui (1) siapa pelaksana implementasi kebijakan, (2) bagaimana peranan dari masing masing pelaksana implementasi (batasan kewenangan), (3) bagaimana pelaksanaan koordinasi di dalam pelaksanaan implementasi

Pelaksana implementasi kebijakan penataan, pembinaan dan pengawasan Toko Modern tidak hanya dilakukan oleh 1 OPD (Organisasi Perangkat Daerah), namun 
melibatkan lebih dari 1 OPD. Di dalam Implementasi Kebijakan, masing masing pelaksana implementasi telah memiliki tugas dan kewenangan sesuai dengan Tupoksi

Faktor pendukung ditinjau dari Context adalah (1) Telah terbentuknya Tim Teknis Perizinan pada Dinas Penanaman Modal dan Pelayanan Terpadu Satu Pintu dan Tenaga Kerja Kabupaten Pekalongan (2) Telah ada pembagian kewenangan yang jelas di dalam pelaksanaan Implementasi Kebijakan

Faktor penghambat ditinjau dari Context adalah (1) Personil yang terlibat dalam penerjunan ke lapangan (survey) sering kali Tim tidak lengkap, sehingga koordinasi menjadi kurang lancar. (2) Terbatasnya personil Satpol PP dan PPNS dalam pelaksanaan pembinaan, pengawasan, penyuluhan dan penegakan Perda.

\section{Commitment}

Implementasi Kebijakan Toko Modern jika dilihat dari Commitment bertujuan untuk mengetahui bagaimana komitment implementator dalam implementasi kebijakan

Implementasi Kebijakan Toko Modern di Kecamatan Kajen belum dilaksanakan secara menyeluruh dan sungguh sungguh oleh pelaksana implementasi baik dalam tahap penataan, pembinaan ataupun pengawasan. Tidak ada ketegasan OPD dalam penegakan Perda, pembinaan masih setengah hati dan pengawasanyang tidak berjalan.

Faktor pendukung ditinjau dari Commitment adalah (1) Sudah tersedianya regulasi yang mendukung Implementasi Kebijakan (2) ASN yang berada pada OPD pengampu Implementasi Kebijakan Toko Modern telah menandatani Perjanjian Kinerja dan Pakta Integritas.

Faktor penghambat ditinjau dari Commitment adalah (1) Kondisi Kota Kajen yang masih dalam tahap perkembangan, sehingga keberadaan Toko Modern dirasakan mampu untuk membuka simpul simpul keramaian, sehingga menyebabkan pelaksana implementasi kebijakan menjadi tidak tegas dalam mensikapi keberadaan Toko Modern. (2) Belum ada komitmen terhadap pengawasan yang baik pemberian izin maupun penegakan Perda

\section{Clients and Coalitions}

Client and Coalitions dalam implementasi kebijakan adalah bagaimana dukungan dari klien dan koalisi yang kepentingannya ditingkatkan atau terancam oleh Kebijakan yang ada. Pada penelitian ini ingin diketahui bagaimana tanggapan dari masyarakat dan Toko Modern itu sendiri. 
Dukungan Clients (Toko Modern) berupa kesiapan memenuhi regulasi yang ada, mereka siap menutup Toko Modern jika masa izin opersional saat ini habis pada tahun 2018. Namun pada sisi lain Toko Modern menghambat Implementasi Kebijakan, seperti tidak mengurus Izin Usaha Toko Modern (IUTM), tidak memberikan laporan kepada Dinas Perindagkop UKM terkait omset penjualan, jumlah UMKM yang bermitra dan pola kemitraan, jumlah tenaga kerja yang diserap.

Dukungan Coalitions dalam implementasi yaitu masyarakat / kelompok masyarakat dan DPRD Kabupaten Pekalongan khususnya Komisi B. Mereka pernah memberikan tekanan berupa Demo dan Rapat Evaluasi sehingga mampu mendorong penutupan Toko Modern yang tidak memiliki izin.

Faktor pendukung ditinjau dari Client and Coalitions adalah (1) Kondisi lingkungan yang kondusif sehingga antara Pasar Modern dan Toko Rakyat tidak terjadi persaingan, masing masing telah memiliki segmen konsumen sendiri (2) Dukungan dari beberapa Toko Modern yang telah menjalin kemitraan dengan UKM, dan adanya program SSP (Sales Store Point) (3) Adanya itikad baik dari Toko Modern berjejaring yang saat ini izin tidak sesuai Perda akan mengikuti regulasi yang ada. Siap untuk menutup Toko Modern jika batas izin telah habis (4) Tekanan dari masyarakat dan DPRD Kabupaten Pekalongan dalam upaya penertiban Toko Modern.

Faktor penghambat ditinjau dari Client and Coalitions adalah (1) Masih terbatasnya pemahaman masyarakat terhadap kebijakan penataan, pembinaan dan pengawasan Toko Modern. (2) Rendahnya kesadaran Toko Modern untuk mengurus Izin Usaha Toko Modern.

\section{PENUTUP}

\section{Kesimpulan}

Implementasi Penataan Toko Modern di Kecamatan Kajen belum berjalan sesuai Peraturan Daerah Nomor 1 tahun 2014 sebagaimana telah diubah dengan Peraturan Daerah Nomor 10 Tahun 2015. Penataan Toko Modern sudah mengacu Rencana Tata Ruang Wilayah Kabupaten Pekalongan Tahun 2011-2031, namun belum ada Rencana Detil Tata Ruang (RDTR) Kecamatan Kajen dan pengaturan zonasi.Pendirian Toko Modern di Kecamatan Kajen sudah memenuhi ketentuan Garis Sempadan Bangunan (GSB) namun belum memenuhi ketentuan jarak dari Pasar Tradisional, tidak memenuhi ketentuan pendirian pada satu sisi dalam ruas jalan yang sama.Operasional Toko Modern 
belum semuanya telah mengantongi Izin Usaha Toko Modern (IUTM), baru 3 Toko yang memiliki izin.. Masih banyak yang dalam proses perizinan bahkan terdapat 4 (empat) Toko Modern yang belum memiliki izin sudah beroperasional.

Implementasi Pembinaan Toko Modern di Kecamatan Kajen belum dilaksanakan secara optimal. Komponen dari Pembinaan meliputi perlindungan, pemberdayaan dan penataan. Peranan perlindungan memiliki keterkaitan yang kuat dengan penataan. Dimana tujuan dari penataan dan perlindungan adalah pasar tradisional, usaha mikro, kecil, menengah dan koperasi terlindungi dari persaingan yang tidak sehat dengan pasar modern, toko swalayan dan sejenisnya. Dalam pelaksanaanya komponen ini masih belum optimal, karena pendirianToko Modern masih banyak yang belum memenuhi ketentuan jarak dari Pasar Tradisional.

Kemitraan yang diharapkan dapat terjalin dengan UKM belum dapat terlaksana khususnya oleh Toko Modern Berjejaring. Kemitraan dengan UKM baru dapat dilaksanakan oleh Toko Modern Non Berjejaring.

Implementasi Kebijakan Pengawasan Toko Modern di Kecamatan Kajen belum berjalan dengan baik. Walaupun pernah dilaksanakan Penertiban terhadap Toko Modern, namun masih banyak Toko Modern yang beroperasional belum memiliki Izin Usaha Toko Modern (IUTM) dan memiliki jam operasional yang tidak sesuai dengan ketentuan regulasi. Selain itu dari Toko Modern di Kecamatan Kajen tidak pernah menyampaikan laporan kepada Dinperindagkop UKM terkait Jumlah dan jenis izin usaha, omset penjualan, jumlah UMKM yang bermitra dan pola kemitraannya, jumlah tenaga kerja yang terserap. Pengawasan berupa monitoring di lapangan yang telah dilaksanakan masih sangat terbatas, yaitu kerjasama dengan Badan POM dalam melaksanakan pengawasan batas kadaluarsa produk.

\section{Rekomendasi}

Rekomendasi sebagai masukan kepada pelaksana implementasi dan peneliti selanjutnya (1) Perlu pembinaan lebih intensif terhadap seluruh Toko Modern yang ada di Kabupaten Pekalongan, tidak hanya Toko Modern Berjejaring. Pembinaan berupa sosialisasi kebijakan, koordinasi rutin untuk mengoptimalkan pelaporan dan , pendampingan terhadap kemitraan antara Toko Modern dan UKM (2) Memberi pembekalan, pendampingan kepada pelaku UKM sehingga mampu menyediakan produk memenuhi syarat sehingga dapat bermitra dengan Toko Modern. Seperti pelatihan PIRT 
(Izin Sertifikasi Laik Higiene Sanitasi Usaha Rumah Tangga Pangan), Pelatihan pengemasan produk. (3) Perlu meningkatkan koordinasi dan kinerja Tim Teknis Perizinan (4) Perlu adanya penambahan personil Satpol PP dan PPNS agar pembinaan, pengawasan dan penyuluhan Peraturan Daerah secara umum dan perizinan Toko Modern pada khususnya menjadi lebih optimal. (5) Perlu peningkatan kapasitas kepada pelaksana implementasi kebijakan toko modern terhadap pemahaman regulasi Toko Modern, melalui sosialisasi kebijakan, pelatihan Standar Pelayanan dan Standar Operasional Prosedur (6) Perlunya penambahan motivasi dan ketegasan kepada pelaksana implementasi dari pengambil kebijakan di Pemerintah Kabupaten Pekalongan. (7) Perlu adanya penelitian lebih lanjut yang memberikan perhatian kepada substansi dari Kebijakan yang ada saat ini terkait Penataan, pembinaan dan Pengawasan Toko Modern di Kabupaten Pekalongan. (8) Perlunya peningkatan pemahaman masyarakat dan pelaku usaha Toko Modern terhadap kebijakan penataan, pembinaan dan pengawasan toko modern misalnya melalui sosialisasi.

\section{DAFTAR PUSTAKA}

Amin, Danial El. 2011. Tesis : Dampak Pasar Modern terhadap Pedagang di Pasar Tradisional di Kecamatan Ciledug Kabupaten Cirebon. Magister Perencanaan dan Kebijakan Publik. Universitas Indonesia.

Bappeda Litbang Kabupaten Pekalongan, 2016. RPJMD Kabupaten Pekalongan 2016 2021. Bappeda Litbang Kabupaten Pekalongan.

BPS Kabupaten Pekalongan, 2018. Kabupaten Pekalongan Dalam Angka 2018. Badan Pusat Statistik Kabupaten Pekalongan.

Dunn, William, 2003, Pengantar Analisis Kebijakan Publik edisi Kedua,: Gadjah Mada University Press. Yogyakarta

Gilarso, T. 2004. Pengantar Ilmu Ekonomi Makro-Edisi Revisi. Kanisius. Yogyakarta.

Inu Kencana Syafiie, 2006, Ilmu Administrasi Publik (Edisi Revisi), Jakarta : Rineka Cipta.

Keban, Yeremias, 2008, Enam Dimensi Strategis Administasi Publik Konsep, Teori, dan Isu, Yogyakarta : Gava Media.

Moleong, Lexy J. 2007. Metodologi penelitian kualitatif. Bandung: PT Remaja Rosdakarya. Bandung 
Najam, Adil. 1995. Learning from the Literature on Policy Implementation : A Synthesis

Perspective. International Institute for Applied Systems Analysis. Austria.

Nugroho, Riant, 2012, Public Policy., PT Elec Media Komputindo. Jakarta

Nugroho, Riant, 2014. Metode Penelitian Kebijakan. Pustaka Pelajar. Yogyakarta.

Sarwono, Jonathan. 2006. Metode Penelitian Kuantitatif dan Kualitatif. Graha Ilmu. Yogyakarta.

Sugiyono, 2014. Metode Penelitian Manajemen. Alfabeta. Bandung.

Tachjan, 2006. Implementasi Kebijakan Publik. AIPI. Bandung

Peraturan Presiden Republik Indonesia Nomor 112 tahun 2007 tentang Penataan dan

Pembinaan Pasar Tradisional, Pusat Perbelanjaan dan Toko Modern

Peraturan Menteri Perdagangan Republik Indonesia Nomor 56/M-DAG/PER/9/2014

tentang Perubahan Atas Peraturan Menteri Perdagangan Nomor 70/M-

DAG/12/2013 tentang Pedoman Penataan dan Pembinaan Pasar Tradisional, Pusat

Perbelanjaan dan Toko Modern

Peraturan Daerah Kabupaten Pekalongan Nomor 10 Tahun 2015 tentang Perubahan Atas

Peraturan Daerah Kabupaten Pekalongan Nomor 1 Tahun 2014 tentang Penataan,

Pembinaan dan Pengawasan Pasar Tradisonal, Pusat Perbelanjaan dan Toko Modern

Peraturan Bupati Pekalongan Nomor 23 Tahun 2016 tentang Petunjuk Pelaksanaan

Peraturan Daerah Kabupaten Pekalongan Nomor 1 Tahun 2014 tentang Penataan,

Pembinaan dan Pengawasan Pasar Tradisional, Pusat Perbelanjaan dan Toko

Modern sebagaimana telah diubah dengan Peraturan Daerah Kabupaten Pekalogan

Nomor 10 Tahun 2015 tentang Perubahan Atas Peraturan Daerah Kabupaten

Pekalongan Nomor 1 Tahun 2014 tentang Penataan, Pembinaan dan Pengawasan

Pasar Tradisional, Pusat Perbelanjaan dan Toko Modern.

Peraturan Bupati Pekalongan Nomor 45 Tahun 2016 tentang Kedudukan, Susunan

Organisasi, Tugas dan Fungsi Serta Tata Kerja Dinas Daerah.

Keputusan Kepala Dinas Penanaman Modal dan Pelayanan Terpadu Satu Pintu dan

Tenaga Kerja Nomor 916/32 Tahun 2017 tentang Penetapan Standar Pelayanan

Dinas Penanaman Modal dan Pelayanan Terpadu Satu Pintu dan Tenaga Kerja

Keputusan Kepala Dinas Penanaman Modal dan Pelayanan Terpadu Satu Pintu dan

Tenaga Kerja Nomor 916/33 Tahun 2017 tentang Penetapan Standar Operasional 
Prosedur Dinas Penanaman Modal dan Pelayanan Terpadu Satu Pintu dan Tenaga Kerja

http://www.pekalongankab. go.id/informasi/berita/berita-lokal/7649-perda - nomor - 5 dan - nomor-10 - tahun-2015-disosialisasikan, 22 Oktober 2015

http://www.minimarketrak.com/blog/potensi-bisnis-minimarket, 1 Januari 2017)

http://www.ekbis.sindonews.com/read/1245272/34/mendag-ungkap-penyebabminimarket-dekat-pasar-tradisional-1507094190 Rabu, 4 Oktober 2017

https://finance.detik.com/berita-ekonomi-bisnis/d-3670530/ada-30-ribu-toko-moderndi-ri-bahayakah-bagi-pasar-tradisional - 4 Oktober 2017): 